doi:10.17659/01.2020.0044

Journal of Case Reports 2020;10(3):166-169

\title{
Double The Bet: Solving Vaccine Against Hepatitis B Failed Seroconversion In Health Professionals
}

\author{
Nayara de Paula Passarin ${ }^{1}$, Danielle Höring Grubert ${ }^{1}$, Giovanna Locks Silveira ${ }^{2}$, Simone Bonafé ${ }^{1}$, Luiz Jorge \\ Moreira Neto ${ }^{1}$ \\ ${ }^{1}$ University Center of Maringá (UniCesumar), Maringá, PR, Brazil; ${ }^{2}$ Universidade do Sul de Santa Catarina (UNISUL), Palhoça, \\ SC, Brazil.
}

\section{Corresponding Author: \\ Dr. Nayara de Paula Passarin \\ Email: naydepaula@gmail.com}

This is an Open Access article distributed under the terms of the Creative Commons Attribution License (creativecommons.org/ licenses/by/3.0).

Received

Accepted

Published

November 23, 2019

June 22, 2020

August 15, 2020

\begin{abstract}
Background: Hepatitis B virus infection is a worldwide health problem, among the most exposed groups are health professionals. The full vaccination scheme promotes protection by forming antibodies against the virus, but about $10 \%$ of individuals do not achieve protective titers. Healthcare workers failing to respond to initial hepatitis $B$ vaccination might be vulnerable to hepatitis $B$ virus infection. A case of a healthcare professional who failed seroconversion by the usual regimen and who responded to an alternative regimen is described within' this article. Case Report: ANG, 30 years old, nurse, looks for an infectology service for not presenting seroconversion to the vaccine, confirmed by the absence of titers that remained negative when performing booster dose. Negative investigation for immunodeficiency, deficiency of vitamin B12, zinc and negative anti-HBs were detected. The approach was to correct nutritional deficiencies and to administer the extended vaccination schedule used in chronic kidney diseases patients. Two months after the last dose, the serological tests showed seroconversion. Conclusion: The immunization regimen used for immunosuppressed individuals may be a viable alternative for patients not responding to the traditional regimen, becoming an option in populations at higher risk for hepatitis B.
\end{abstract}

Keywords: Hepatitis B Vaccine, Health Personnel, Vaccination, Vitamin B12, Zinc.

\section{Introduction}

Hepatitis B virus (HBV) infection is a worldwide health problem. In Brazil, even with vaccination, 17,000 new cases are detected and reported annually. Among the most exposed groups are sex workers, drug users, people deprived of their freedom and health professionals. HBV transmission occurs through percutaneous parenteral inoculation, unprotected sex and via the placenta [1]. Vaccination is an effective measure to prevent infection being administered intramuscularly at three doses $(0,1$ and 6 months) [2]. A protective response is considered to be the presence of antibody levels (anti-HBs) at rates of $\geq 10 \mathrm{mIU} / \mathrm{mL}$. The complete vaccination scheme induces a protective response of $90 \%$ in adults and children, but $10 \%$ of individuals do not achieve the protective antibody titers [3].

Therefore, it is recommended that populations more exposed to contamination should perform an anti-HBs serology and if the values are lower than recommended, a new HBV vaccination regimen and subsequent serology should be performed. However, if no antibodies are detected weeks after the last dose, the patient is considered unresponsive and an anti-hepatitis $\mathrm{B}$ immunoglobulin is used if there is exposure to the virus. In populations with diseases that cause immunosuppression, the conventional vaccine dose regimen produces a lower response when 
compared to the one of healthy individuals, requiring alternative vaccination schemes aiming to increase their immunogenicity [4].

\section{Case Report}

ANG, a 30-year-old nurse, sought an infectious disease service in the city of Maringá PR for failing to respond to hepatitis $\mathrm{B}$ vaccine after two prior conventional regimens properly performed according to the vaccination card annotations. She had no complaints and used polyvitaminic by own initiative, previous diagnosis of hypothyroidism levothyroxine-controlled with $75 \mu \mathrm{g}$ daily. With no physical examination abnormalities, underwent immunosuppression investigation with normal results, screening for chronic viral hepatitis negative, reduced B12 (251 pg/mL) and zinc $(60 \mu \mathrm{g} / \mathrm{dL})$, and negative anti-HBs $(<3.1 \mathrm{mIU} /$ $\mathrm{mL}$, method limit). The procedure was to use a doubled dose of hepatitis $B$ vaccine at times $0,1,2$ and 6 months and after the first dose the anti-HBs should be dosed to check for a booster response. Oral zinc replacement $30 \mathrm{mg}$ daily for three months and intramuscular cyanocobalamin/ pyridoxine/ thiamine 5,000 mcg once weekly for 6 weeks were also indicated. Upon return consultation, the patient had no complaints and had already received the first two doses vaccination schedule with negative booster, confirming the failure in responding to previous vaccinations, and normalization of B12 (908 pg/mL) and zinc (96 $\mu \mathrm{g} / \mathrm{mL}$ ) levels. The patient returned after completion of the vaccine regimen without any

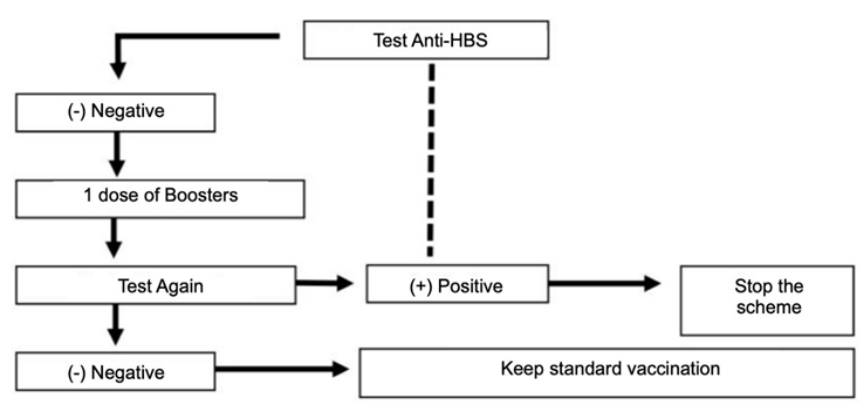

Fig.1: Already vaccinated professionals. adverse event due to vaccination reporting only alopecia despite zinc consumption and a diagnosis of bilateral patellar chondromalacia. The anti-HBs at the end came as $195.81 \mathrm{mIU} / \mathrm{mL}$, indicating that the alternative vaccination regimen reached the goal.

\section{Discussion}

According to World Health Organization (WHO) data, 2 billion people are infected with the hepatitis $B$ virus worldwide and over 600,000 people die each year from complications of the disease $[1,2]$. The recombinant vaccine is effective and accepted worldwide, but some factors decrease the immunological response to the vaccination, including age, obesity, smoking, malnutrition, chronic kidney disease and other causes of immunosuppression. The type of vaccine and the route of administration used may also be influential $[3,4]$.

Health professionals are at constant risk of HBV contamination due to exposure to blood and body fluids, being protective antibody levels in need to be checked after a complete vaccination scheme $[5,6]$. European and American authorities consider titers $\geq 100 \mathrm{mIU} / \mathrm{mL}$ ideal for these professionals as they increase protection against HBV [7]. The initial response rate to the vaccine is known to be $90 \%$, so the current recommendation [Fig.1,2] is

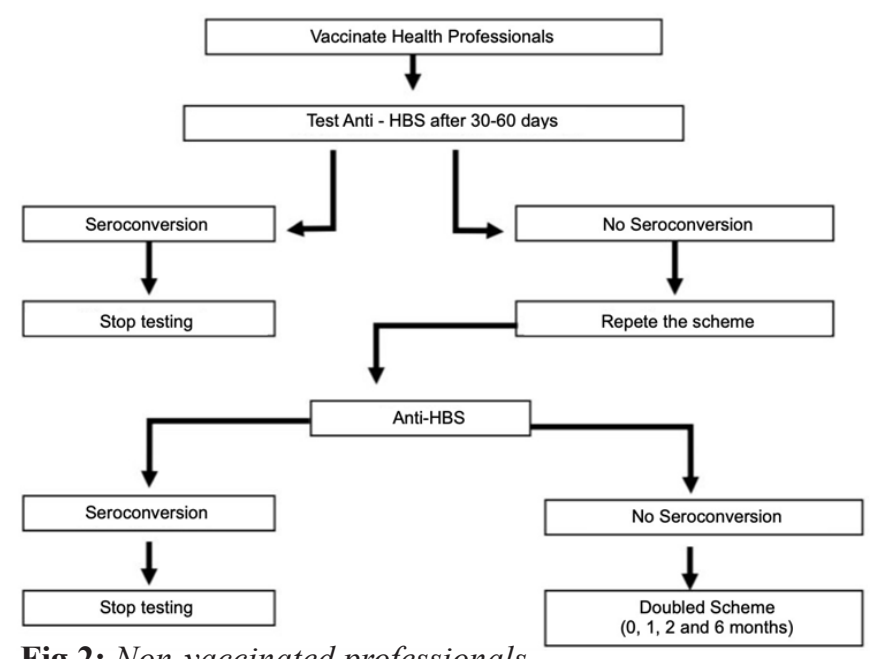

Fig.2: Non-vaccinated professionals. 
to revaccinate patients who did not respond to a first regimen using one of the following alternative approaches: additional vaccine dose, a repetition of the standard regimen, doubled dose $(40 \mu \mathrm{g})$, higher antigen rate vaccine or alternative route of administration. However, studies comparing the above approaches to determine which recommendation is most effective are scarce $[3,5,8]$.

The study by Joukar et al. [3], conducted with 91 health workers who did not respond to the first series of vaccines, compared the use of the $20 \mu \mathrm{g}$ dose (n: 47) with the $40 \mu \mathrm{g}$ dose (n: 44) and found that after the first dose of the doubled vaccine, 93\% seroconversion was observed in individuals in the second group in comparison to the first one (90\%). In a study by Zhen-zi [2] with a high-dose $(60 \mu \mathrm{g})$ vaccine administered in a two-dose schedule with two gap alternatives in 236 young adults (Group A, n: 111, 0-1 month; and Group B, n: 125, 0-2 months) showed high efficacy in inducing a high immunogenic response, demonstrated by seroconversion of $97 \%$ of vaccinated persons, when compared to a third group receiving the standard dose of $20 \mu \mathrm{g}$ in the 0,1 and 6 months (n: 117). This same study points out that the formulation of the doubled dose (40 $\mu \mathrm{g})$ is superior than the standard one $(20 \mu \mathrm{g})$ due to the higher amount of HBsAg protein used in each dose, therefore, the $60 \mu \mathrm{g}$ vaccine used in the above study exceeds the double dose $(40 \mu \mathrm{g})$ in seroconversion [2].

Patients with cancer have immunosuppression, whether due to disease or chemotherapy treatment, and present suboptimal anti-HBs antigen responses. A study by Sodhi et al. [9] compared the use of an alternative vaccination regimen in adult patients with cancer at an accelerated dose, with a doubled vaccination regimen $(40 \mu \mathrm{g})$ against the hepatitis $B$ virus accelerated at 0,1 and 3 weeks before immunosuppression by the chemotherapy treatment, followed by three additional doubled doses after a one month gap between them (Group A: 490 patients). This alternative protocol was compared to the simple three-dose standard $(20 \mu \mathrm{g})$ pattern $(0,1$, and 6 months) performed as a booster in adult cancer patients (Group B: 479 patients). Anti-HB $\mathrm{H}_{\mathrm{S}}$ titers were verified at 3, 6 and 9 months after the termination of the vaccination schedule, and a seroconversion rate with more significant titers was found in group A patients (9 months: $75.9 \%$ ) when compared to Group B (9 months: $49 \%)$.

When evaluating two alternative HBV vaccination strategies (3 doses of $20 \mu \mathrm{g}$ and 4 doses of $40 \mu \mathrm{g}$, both administered intramuscularly) in adult HIV patients, the randomized study by Launay et al. [10] observed an increased response rate 1 month after the last dose of the vaccine in patients receiving 4 doubled doses $(82 \%)$ compared to those receiving 3 single doses (65\%). In the same study, $74 \%$ of patients who received 4 doubled doses had anti-HBs titers of $100 \mathrm{mIU} /$ $\mathrm{mL}$ or greater, an effective protective titer and a long-term response maintainer, but only $41 \%$ of patients in the group receiving only three simple doses reached this value [10].

\section{Conclusion}

The studies converge to state that the use of higher than standard doses, even in alternative time schedules, increases patient seroconversion, whether in immunocompetent or immunocompromised patients. In addition, some alternatives are more onerous making it necessary to develop a guideline with appropriate conducts to serve patients who did not respond to the standard HBV vaccination schedule, especially those who are most frequently exposed. Studies demonstrate a wide range of options, but there is still a need for controlled clinical trials which are designed to evaluate seroconversion rates.

Contributors: NPP, DHG, GLS: manuscript writing original draft preparation, manuscript editing; LJMN, SB: critical inputs into the manuscript; patient management and idea 
conceptualization. NPP will act as study guarantor. All authors approved the final version of the manuscript and are responsible for all aspects of the study.

Funding: None; Competing interests: None stated.

\section{References}

1. Brasil. Ministério da Saúde. Secretaria de Vigilância em Saúde. Departamento de DST, Aids e Hepatites Virais. Protocolo Clínico e Diretrizes Terapêuticas para Hepatite B e Coinfecções. Brasília: Ministério da Saúde, 2017: pp.120.

2. Zhen-Zi W, Ming-Qiang L, Ping W, Zhen-Xing Y, Lin W, Ying Z, et al. Comparative immunogenicity of hepatitis $B$ vaccine with different dosages and schedules in healthy young adults in China. Vaccine. 2016;34:10341039.

3. Joukar F, Mansour-Ghanaei F, Naghipour MR, Asgharnezhad M. Immune responses to single-dose versus double-dose hepatitis B vaccines in healthcare workers not responding to the primary vaccine series: A randomized clinical trial. Hepat Mon. 2016;16:e32799.

4. Cordova E, Miglia I, Festuccia F, Sarlo MG, Scornavacca G, Punzo G, et al. Hepatitis B vaccination in haemodialysis patients: An underestimated problem. factors influencing immune responses in ten years of observation in an Italian haemodialysis centre and literature review. Ann Ig. 2017;29:27-37.
5. Yen $\mathrm{YH}$, Chen $\mathrm{CH}$, Wang LH, Lee CM, Changcchien CS, Lu SN. Study of hepatitis B (HB) vaccine nonresponsiveness among health care workers from an endemic area (Taiwan). Liver International. 2005;25:1162-1168.

6. Ghebrehewet S, Baxter D, Falconer M, Paver K. Intradermal recombinant hepatitis $\mathrm{B}$ vaccination (IDRV) for non-responsive healthcare workers (HCWs). Human Vaccines. 2008;4:280-285.

7. Rendi-Wagner P, Shouval D, Genton B, Lurie Y, Rümke $\mathrm{H}$, Boland G. Comparative immunogenicity of a PreS/S hepatitis $\mathrm{B}$ vaccine in non- and low responders to conventional vaccine. Vaccine. 2006;24:2781-2789.

8. David MC, Há SH, Paynter S, Lau C. A systematic review and meta-analysis of management options for adults who respond poorly to hepatitis $\mathrm{B}$ vaccination. Vaccine. 2015;33(48):6564-6569.

9. Launay O, van der Vliet D, Rosenberg AR, Michel ML, Piroth L, Rey D, et al. Safety and immunogenicity of 4 intramuscular double doses and 4 intradermal low doses vs standard hepatitis B vaccine regimen in adults with HIV-1: a randomized controlled trial. JAMA. 2011;305:1432-1440.

10. Sodhi JS, Raja W, Zargar SA, Showkat A, Parveen S, Nisar S, et al. The efficacy of accelerated, multiple, double-dose hepatitis B vaccine against hepatitis B virus infection in cancer patients receiving chemotherapy. Indian J Gastroenterol. 2015;34(5):372-379. 